\title{
Upgrading and Extending PON by Using In- Band WDM Overlay
}

\author{
Rivael Strobel Penze ${ }^{(1)}$, Joao Batista Rosolem ${ }^{(1)}$, Renato Baldini Filho ${ }^{(2)}$ \\ ${ }^{(1)} \mathrm{CP} q \mathrm{D}-$ Research and Development Center in Telecommunications, Campinas, SP, Brazil \\ E.mail rpenze@cpqd.com.br, rosolem@cpqd.com.br \\ ${ }^{(2)}$ University of Campinas, Campinas, SP, Brazil \\ E.mailbaldini@decom.fee.unicamp.br
}

\begin{abstract}
This paper presents a new approach to upgrade and extend the reach of the current passive optical network (PON) by using wavelength division multiplexing (WDM) in the standardized optical grid of gigabit PON (In-band WDM PON overlay). The aim is to increase the number of optical distribution networks (ODNs) fed by a single fiber while preserving the users bandwidth. In this approach four downstream (DS) wavelength signals are transmitted from an optical line terminal (OLT) to four different ODNs using the standard DS PON spectrum ranging from 1480 to $1500 \mathrm{~nm}$. The upstream (US) signals from the four different ODNs are also wavelength multiplexed within the standardized US PON spectrum ranging from 1270 to $1330 \mathrm{~nm}$. Experimental proofs of concept are presented in a $20 \mathrm{~km}$ PON serving 32 ONTs and in a 58 km extended PON in order to demonstrate the feasibility of this proposal.
\end{abstract}

Index Terms- PON Overlay, PON Stacking, GPON, GEPON CWDM.

\section{INTRODUCTION}

Current passive optical networks (PON), such as gigabit passive optical network (GPON) and gigabit Ethernet passive optical network (GEPON), are recognized as market leaders in optical access deployments. The upgrade or the evolution of these networks has been proposed and analyzed in the literature [1]-[4].

The trivial PON evolution is to increase the transmission bit ratio to $10 \mathrm{~Gb} / \mathrm{s}$ or to use dense wavelength division multiplexing (DWDM) [4]. However there are also some ITU-T studies to implement the concept of a coarse wavelength division multiplexing (CWDM) PON overlay or PON stacking, which are extensions of standard PON equipment based on several independent colored PON systems over a single optical distribution network (ODN) infrastructure and that enable a wavelength level unbundling [5]-[6].

Previous works proposed a CWDM PON overlay network to increase the number of ODNs powered by a single fiber [7]-[9]. In [7] a CWDM PON overlay was proposed to increase fourfold the downstream (DS) network capacity, while maintaining the ability to upstream (US) by $1.25 \mathrm{~Gb} / \mathrm{s}$. According to [7] the optical line terminal (OLT) is replaced keeping the optical network terminals (ONTs) unchanged. Three new OLT with wavelengths at $1430 \mathrm{~nm}, 1450 \mathrm{~nm}$ and $1470 \mathrm{~nm}$, in addition 
to the standardized PON channel of $1490 \mathrm{~nm}$ are used as downstream channels to the ONTs. The same authors also analyze this topology in [8] applied for an extended reach PON. In [9] it is presented the overlay of five gigabit signals operating between $1531 \mathrm{~nm}$ to $1611 \mathrm{~nm}$ over a working GPON.

Nowadays, these DS CWDM wavelengths are incompatible with the optical bandwidth of the current ONT transceivers which work in the range from $1480 \mathrm{~nm}$ to $1500 \mathrm{~nm}$ (S band) according ITUT G.984.2 [10]. Therefore the ONT transceiver filter must be re-designed. However, ONT transceivers are currently in mass production which makes difficult to apply this proposal in the current PON architecture.

This paper presents a new approach to upgrade the current PON by using WDM in the standardized PON optical grid. This approach is named In-band PON overlay. Four channels chosen in S band $(1482,1486,1492$ and $1496 \mathrm{~nm})$ are transmitted from the OLT to four different ODNs. The upstream signals $(1270,1290,1310$ and $1330 \mathrm{~nm})$ from the four different ODNs are also multiplexed within the standardized OLT O band receiver spectrum. This procedure allows the network to be expanded preserving the same standardized PON spectrum. In addition, the user bandwidths are kept unchanged despite of the network upgrading. The network topology is described and an experimental proof of concept is presented in order to demonstrate the feasibility of this proposal. In addition, we show the feasibility to increase the reach of the proposed network by using SOA's based extender. It is also presented the experimental results of the extended network operation for four downstream channels centered in $1490 \mathrm{~nm}$ and four upstream channels centered in $1300 \mathrm{~nm}$, using downstream and upstream transmission rate of $2.5 \mathrm{~Gb} / \mathrm{s}$ in a $20 \mathrm{~km}$ PON serving 32 ONTs and in a $58 \mathrm{~km}$ extended PON.

\section{PON OVERLAY ARCHITECTURES}

\section{A. Previous CWDM PON overlay grids}

The traditional PON overlay architecture is shown in Fig. 1. Several PONs use different CWDM wavelengths for DS and US signals [11]. Therefore, the total capacity of the feeder fiber is increased, making this architecture very attractive to extend the reach of feeder fiber. Since, the fiber plant cost increases with the reach, sharing various ODNs in the same feeder is an effective way for network operators to decrease the costs [11]. 


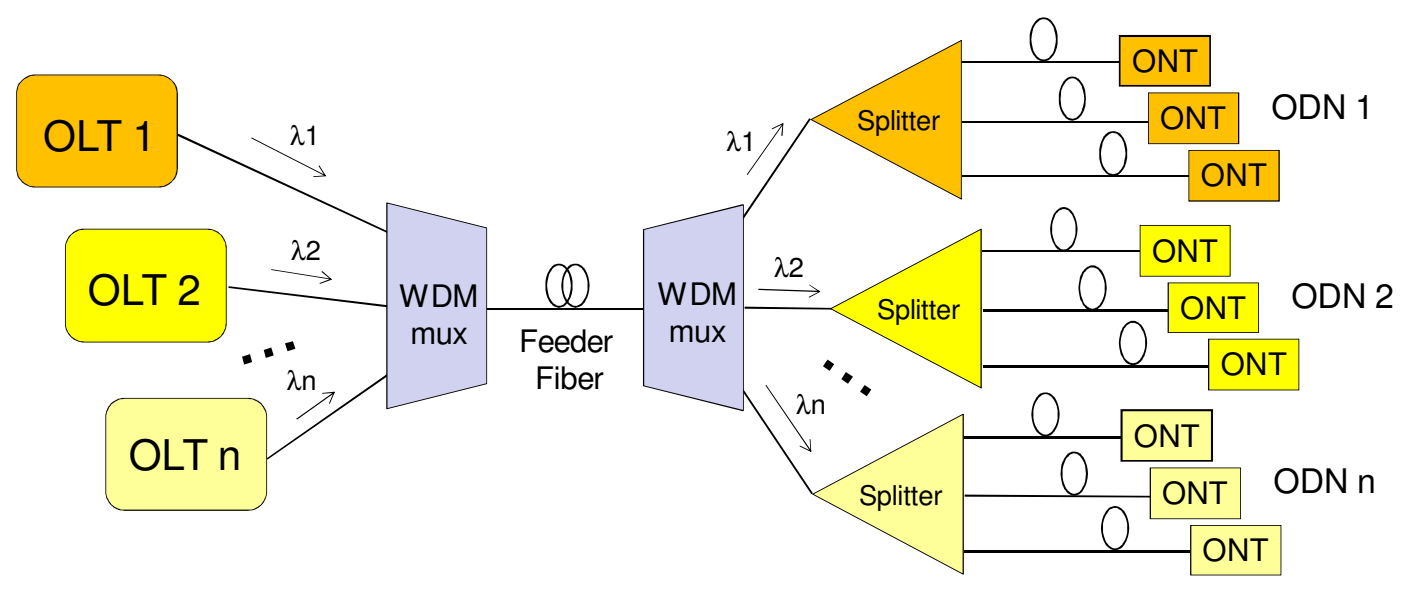

Fig. 1. Generic diagram for a CWDM PON overlay.

Fig. 2 shows the CWDM optical grid [12] available for PON overlay operation. The spectra reserved for GPON systems [10], XGPON [13] and Video Overlay [14] systems are also shown in this figure. These systems will coexist in the same current implanted optical network establishing probably the first standardized PON overlay.

Notice that in the CWDM PON overlay demonstration described in [6] the DS wavelengths are $1430 \mathrm{~nm}, 1450 \mathrm{~nm}, 1470 \mathrm{~nm}$ and $1490 \mathrm{~nm}$ (See Fig. 2). In the demonstration described in [8] the DS wavelengths are $1531 \mathrm{~nm}, 1551 \mathrm{~nm}, 1571 \mathrm{~nm}, 1591$ and $1611 \mathrm{~nm}$. None of these demonstrations includes grid for US channels.

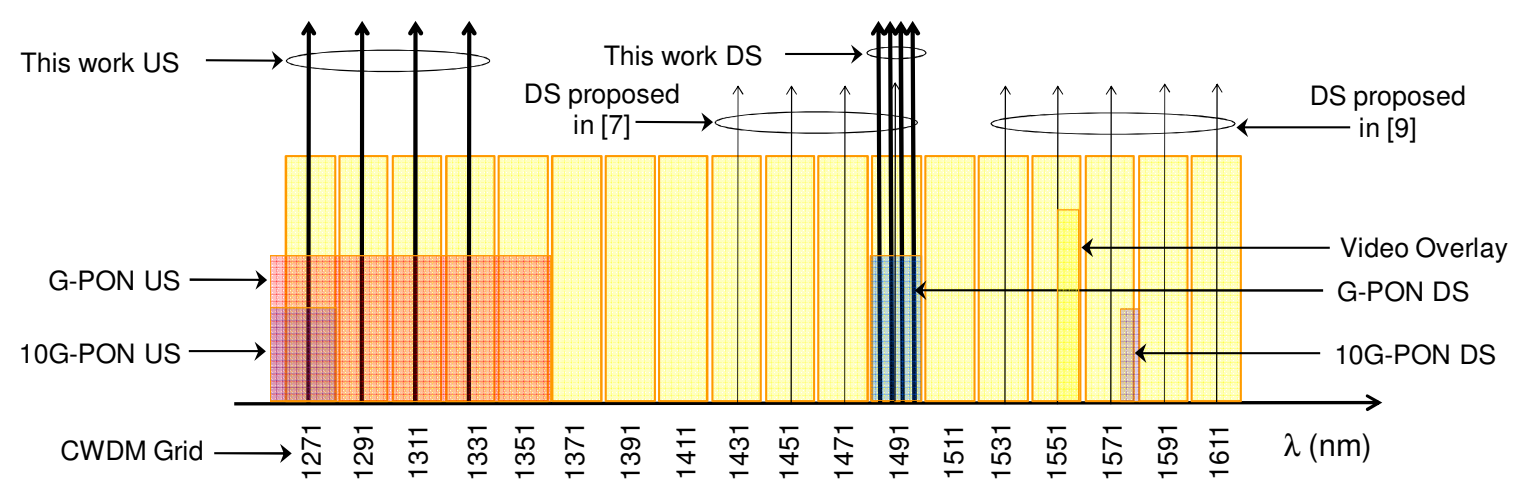

Fig. 2. Available spectrum grid for a WDM PON overlay.

\section{B. In-band WDM PON overlay architecture}

The proposed in-band WDM PON overlay architecture is shown in Fig. 3. The basic concept is to increase the number of ODNs fed by just one single fiber. This PON architecture uses four S band wavelengths transmitted from an OLT to four different ODNs. The experiment makes use of selected commercial distributed feedback (DFB) lasers that operated in the standardized PON DS spectrum band $(1480 \mathrm{~nm}$ to $1500 \mathrm{~nm})$. The downstream wavelengths are 1482, 1487, 1492 and $1497 \mathrm{~nm}$ (Fig.2). The $5 \mathrm{~nm}$ spacing between the wavelengths is allowed to match with the grid of selected commercial S band WDM multiplexers (mux) used in Raman amplifiers. 


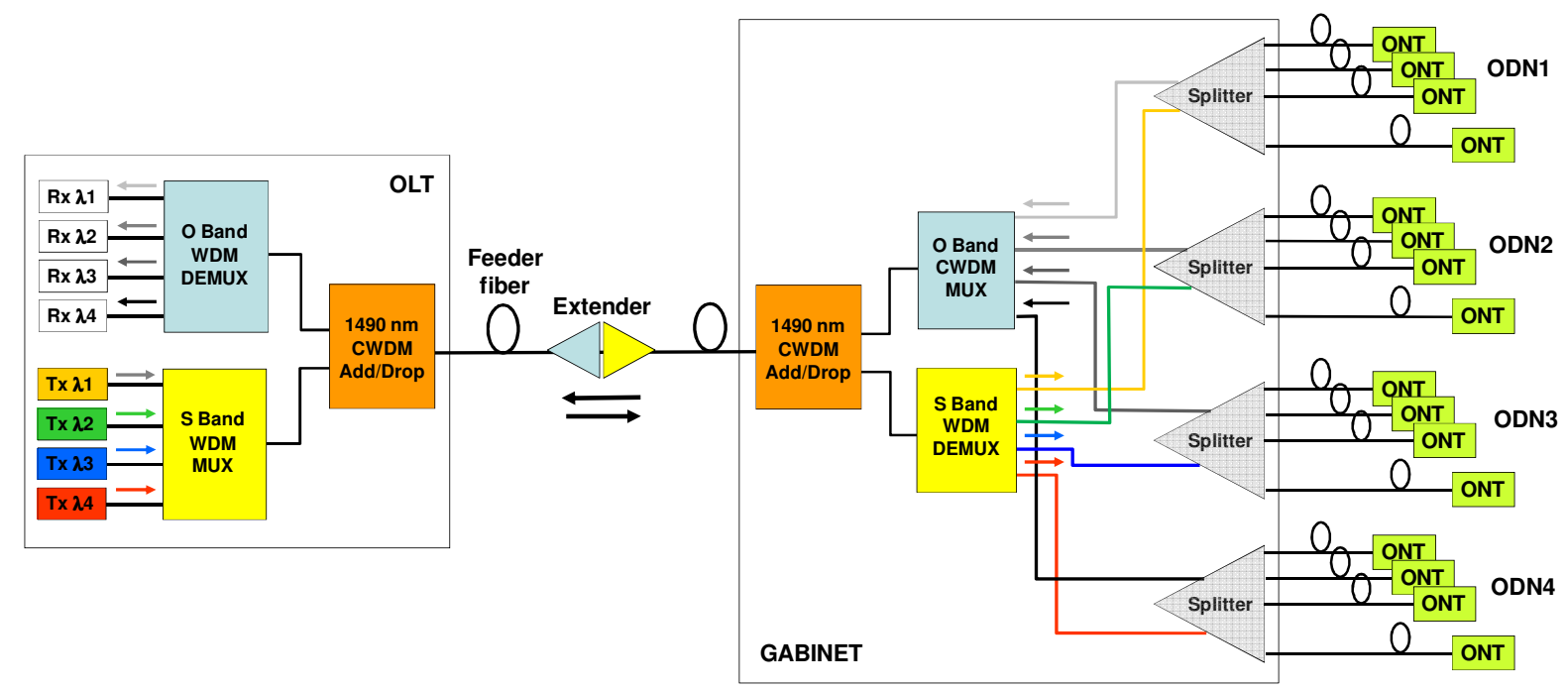

Fig. 3. Proposed in band WDM PON overlay architecture using standardized transceiver's bands.

In the OLT the four $\mathrm{S}$ band channels are multiplexed in the feeder fiber by means of one $\mathrm{S}$ band mux and one 1x2 $1490 \mathrm{~nm}$ add/drop CWDM filter. The same add/drop filter connects the upstream channels to one $1 \times 4 \mathrm{O}$ band CWDM demultiplexer (demux) that is followed by the optical OLT receivers.

In the far end of the feeder fiber, the downstream channels and the upstream channels are again routed by other 1x2 $1490 \mathrm{~nm}$ add/drop CWDM filter. The downstream channels are inserted into four ODNs by means of one $\mathrm{S}$ band demux. Notice that each ODN contains one $2 \mathrm{xN}$ splitter.

All ONTs transmitters, belonging to a given ODN, send the upstream signals using a specific CWDM channel. The wavelengths for the four OLTs are in the range from $1270 \mathrm{~nm}$ to $1330 \mathrm{~nm}$ (Fig.2). These wavelengths have been chosen by the following reasons: they are within the standardized OLT receiver spectrum; they are CWDM channels standardized by ITU-T [12]; they have already been used in deployed PONs [5], and also they allow PON extension by using semiconductor optical amplifiers (SOAs) with spectrum gain matched to these wavelengths [15].

The upstream channels, after passing through the splitters, are multiplexed by means of one $1 \times 4 \mathrm{O}$ band CWDM mux and they are connected in the feeder fiber by the 1x2 $1490 \mathrm{~nm}$ add/drop CWDM filter. The $1 \times 4 \mathrm{O}$ band CWDM mux may be replaced by one $1 \times 4$ splitter if its insertion loss can be absorbed by the link power budget.

In the OLT, other 1x2 $1490 \mathrm{~nm}$ add/drop CWDM filter directs the upstream signals to a 1x4 O band CWDM demux and, finally, to the optical receivers.

A PON extender based on the use of SOAs has also been utilized before the ODNs. This application is better described in the next section. 


\section{PROOFS OF CONCEPT}

\section{A. Network Upgrading}

The in-band WDM PON overlay architecture shown in Fig. 3 was firstly implemented without a PON extender. The feeder fiber length was $20 \mathrm{~km}$ composed by a standard single mode fiber. The OLT and the ONT channels performance were evaluated in terms of bit error rate (BER), using transmission bit rate of $2.5 \mathrm{~Gb} / \mathrm{s}$, and a pseudo-random binary sequence (PRBS) with length equal to $2^{23}$-1. Fig. 4 shows the OLT and OLT prototype diagrams used only to demonstrate our proposal. In the OLT, four $\mathrm{S}$ band DFB lasers operating in continuous wave $(\mathrm{CW})$ power inject their signals in one Mach-Zender (MZ) LiNbO3 modulator by means of the S band mux. Polarization controllers are used to adjust the right polarization of the signals in the modulator input. The electrical signal of a pattern generator is amplified before injected in the MZ modulator.

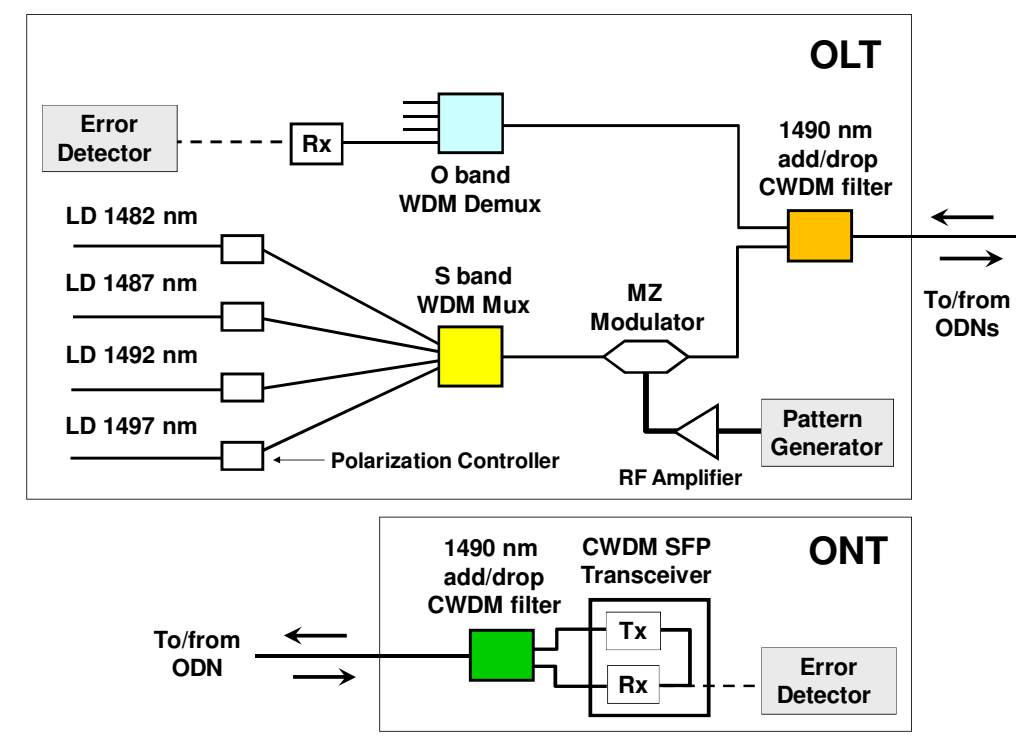

Fig. 4. Details of the OLT and OLT prototype diagrams.

Each ONT uses a commercial CWDM small form pluggable (SFP) transceivers and one 1x2 1490 $\mathrm{nm}$ add/drop CWDM filter to connect the downstream channel in the receiver and the upstream channel in the 2x32 splitter arm. The ONT and OLT receivers use APD (Avalanche Photo Diode) detectors with $-31 \mathrm{dBm}$ average sensitivity (ONT) and $-33.5 \mathrm{dBm}$ average sensitivity (OLT). The average optical power transmitted by each laser in $\mathrm{S}$ band is $1.3 \mathrm{dBm}$ and $0 \mathrm{dBm}$ for $\mathrm{O}$ band CWDM.

Fig. 5 shows the total insertion loss/insulation of (a) S band demultiplexer, (b) 1490 add/drop CWDM and (c) $\mathrm{O}$ band demultiplexer. The maximum insertion losses for multi/demultiplexers are: $\mathrm{S}$ band $\mathrm{WDM}$ mux/demux $=1.6 \mathrm{~dB}, \mathrm{O}$ band $\mathrm{WDM}$ mux/demux $=1.8 \mathrm{~dB}, 1490 \mathrm{~nm}$ add/drop CWDM filter $=0.7 \mathrm{~dB}$ and the $2 \times 32$ Splitter $=15.8 \mathrm{~dB}$. The fiber attenuation at $\mathrm{O}$ band ranges from 0.39 $\mathrm{dB} / \mathrm{km} \mathrm{dB}$ at $1270 \mathrm{~nm}$ to $0.31 \mathrm{~dB} / \mathrm{km}$ at $1330 \mathrm{~nm}$. At $\mathrm{S}$ band, the average fiber attenuation is 0.22 $\mathrm{dB} / \mathrm{km}$. 

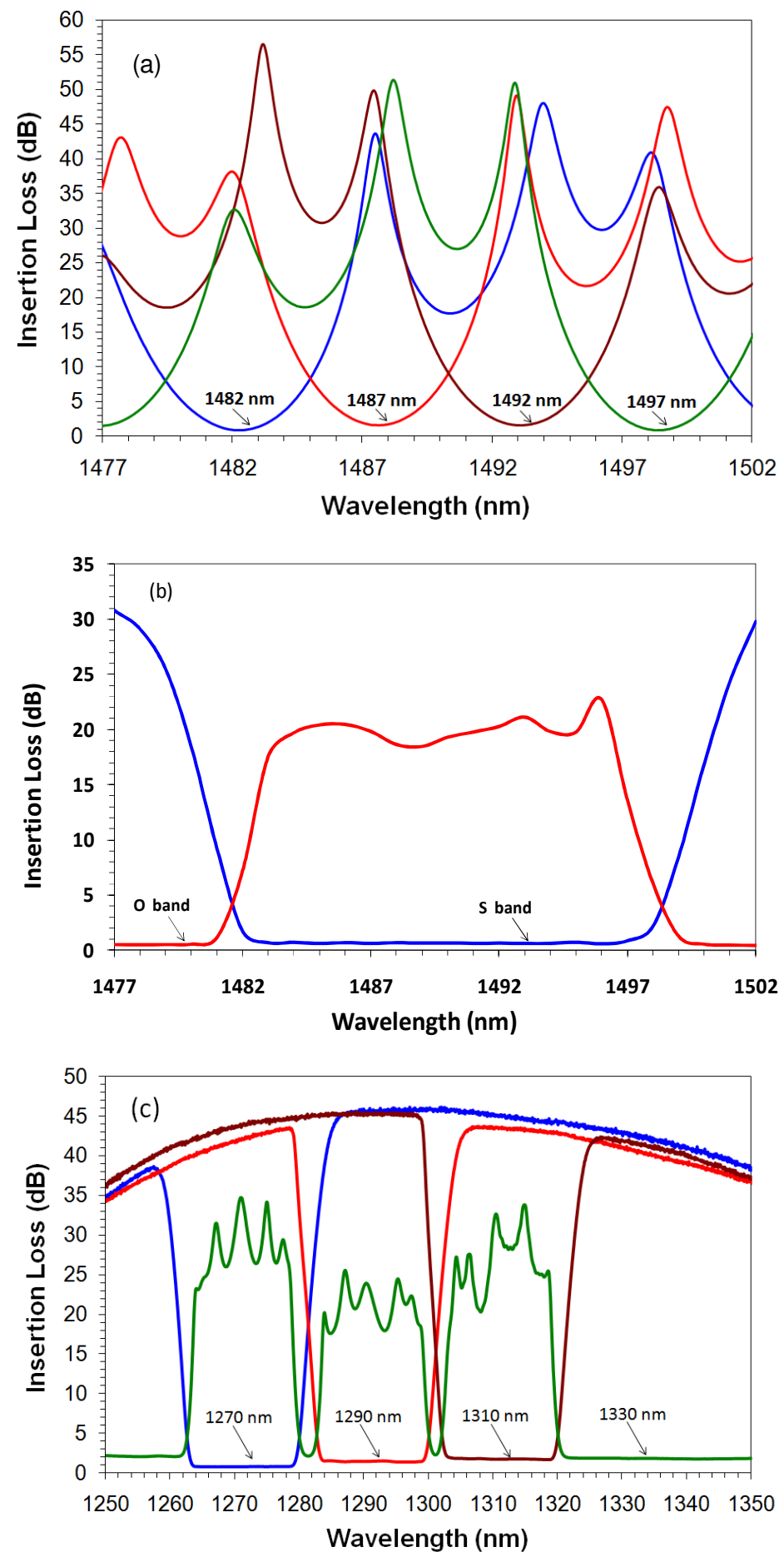

Fig. 5. Mux loss/insulation for (a) S band, (b) 1490 add/drop CWDM and (c) O band.

Fig. 6(a) shows the BER performance evaluation for $\mathrm{S}$ band channels and Fig. $6(\mathrm{~b})$ shows it to $\mathrm{O}$ band channels measured, respectively, in the ONT and in OLT with and without fiber (BTB). The power penalty is null at $\mathrm{BER}=1 \times 10^{-12}$ for downstream channels and it is around $2 \mathrm{~dB}$ for upstream channels. The power penalty for upstream channels is entirely absorbed by the system optical budged. The margin for the downstream and upstream channels is $2 \mathrm{~dB}$ at BER $=1 \times 10^{-12}$. Fig. 7 shows the spectrum in OLT of transmitted downstream and received upstream channels. 

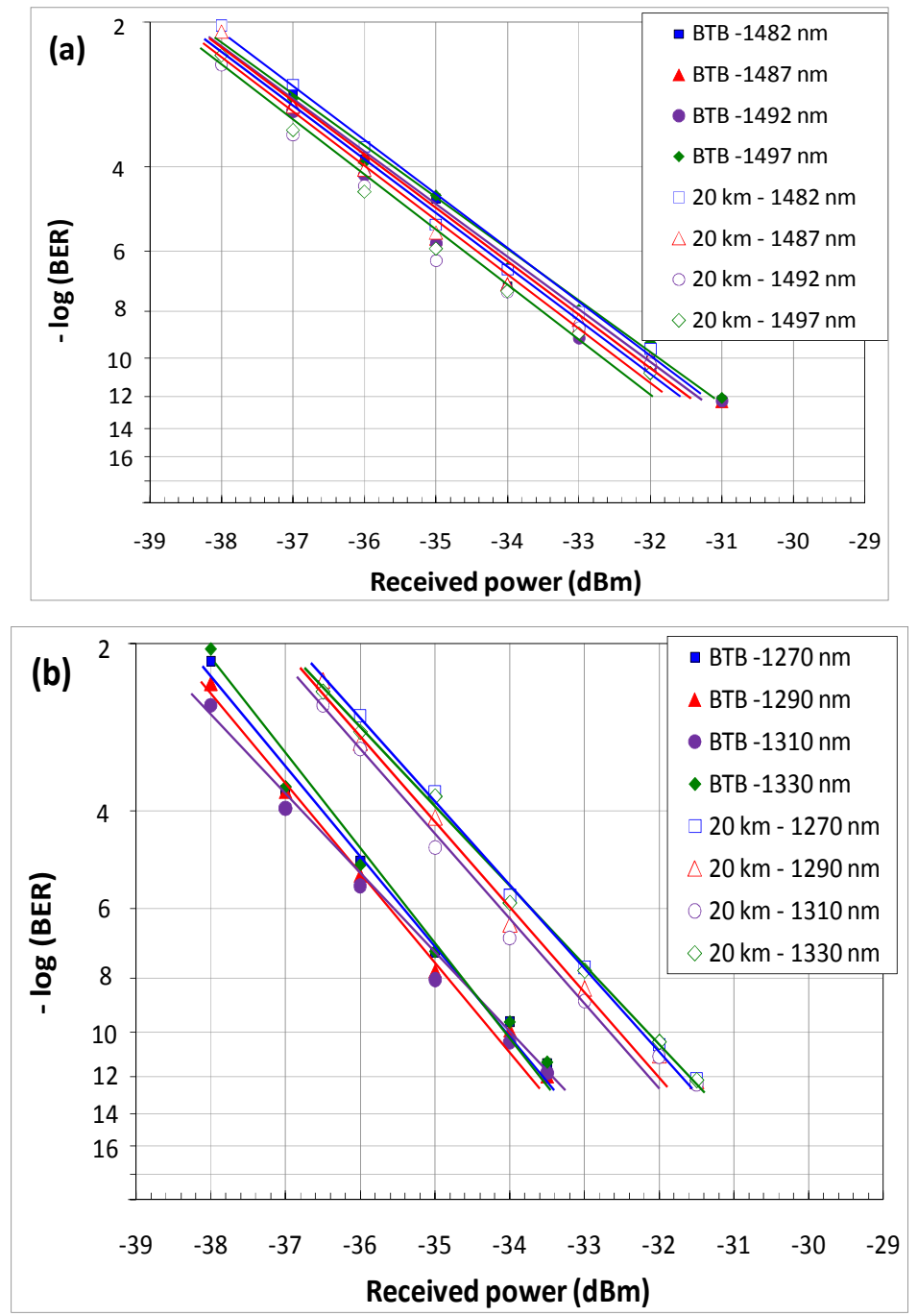

Fig. 6. The BER performance evaluation for (a) S band downstream channels measured in ONT and (b) O band upstream channels measured in OLT.



Fig. 7. Optical spectrum of downstream and upstream signals in OLT for a $20 \mathrm{~km}$ reach PON. 


\section{B. Network Upgrading and Extending}

In order to verify the reach increase of in-band WDM PON overlay architecture, a PON extender based in SOAs is used. The bi-directional SOAs circuit is presented in Fig. 8. It is utilized a $1310 / 1490 \mathrm{~nm}$ fuser coupler to connect the input and output of two commercial SOAs, one for 1310 $\mathrm{nm}$ spectral band and other for $1490 \mathrm{~nm}$ spectral band. Fig. 3 shows the extender position in the fiber link, i.e., after $50 \mathrm{~km}$ from the OLT. Following the PON extender it is deployed $8 \mathrm{~km}$ fiber. These two fiber links have same attenuation as for the $20 \mathrm{~km}$ link previously described.

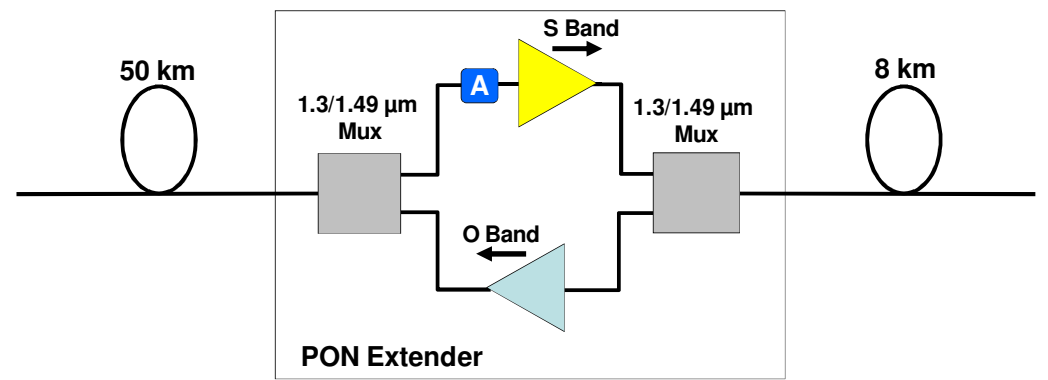

Fig. 8. Details of the bidirectional PON extender.

Typical characteristics of the SOAs are: loss signal gain greater than $15 \mathrm{~dB}$ in $1490 \mathrm{~nm}$ and in 1310 $\mathrm{nm}$, operation current equal to $200 \mathrm{~mA}$, and polarization sensitivity better than $1.5 \mathrm{~dB}$. An optical attenuator is used in the input of the $1490 \mathrm{~nm}$ SOA to avoid BER degradation caused by cross gain modulation in nonlinear regime. Fig. 9 shows the spectrum of the PON extender outputs according to its position presented in Fig. 1. Notice that the gain bandwidth is $15 \mathrm{~nm}$ in $\mathrm{S}$ band and it is $60 \mathrm{~nm}$ in $\mathrm{O}$ band.

In the position where the extender is utilized the average input power per channel for $\mathrm{S}$ band channels is approximately $-13.5 \mathrm{dBm}(-23.5 \mathrm{dBm}$ after the attenuator) and the gains are $13.5 \mathrm{~dB}$ (1482 $\mathrm{nm}), 13.8 \mathrm{~dB}(1487 \mathrm{~nm}), 13.1 \mathrm{~dB}(1492 \mathrm{~nm})$ and $12.8 \mathrm{~dB}(1497 \mathrm{~nm})$. The gains for $\mathrm{O}$ band channels are (average input power per channel $\approx-24 \mathrm{dBm}): 11.9 \mathrm{~dB}(1270 \mathrm{~nm}), 17.4 \mathrm{~dB}(1290 \mathrm{~nm}), 16.8 \mathrm{~dB}$ $(1310 \mathrm{~nm})$ and $14.1 \mathrm{~dB}(1330 \mathrm{~nm})$.

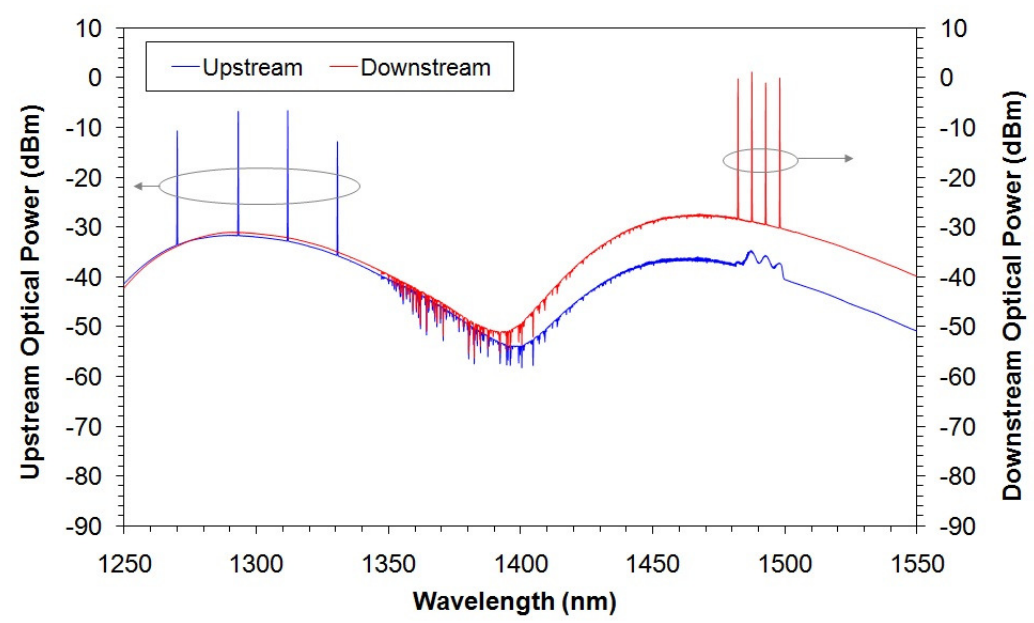

Fig. 9. Optical spectrum in the extender outputs for downstream and upstream channels. 
Fig.10(a) shows the BER performance evaluation for $\mathrm{S}$ band and Fig. 10(b) shows the BER performance evaluation for $\mathrm{O}$ band channels measured in the ONT and in OLT, respectively, compared to BTB measurements. The power penalty is around $7 \mathrm{~dB}$ at BER $=1 \times 10^{-12}$ for $\mathrm{S}$ band channels and it is around $4 \mathrm{~dB}$ for $\mathrm{O}$ band. These penalties are attributed to the signal-to-ASE (Amplified Spontaneous Emission) beat noise process in the optical receivers.

Further experiments were conducted in order to test the ONT receiver performance due to the possible thermal wavelength variation of $S$ band lasers. Since the $S$ band multiplexer/demultiplexer transmission band is not flat (see Fig. 5(a)), the spectral variation of S band lasers can degrade the BER in the ONTs. Figure 11 shows the BER and received power performance of one $\mathrm{S}$ band channel $(1492 \mathrm{~nm})$ measured in an ONT receiver when the wavelength of the laser is thermally changed by $+/-$ $2.5 \mathrm{~nm}$. It is observed that the BER performance is not changed for $+/-0.75 \mathrm{~nm}$ because the optical received power does not change in this range. This specific measurement point was chosen to demonstrate the problems concerned with the channel bandwidth.
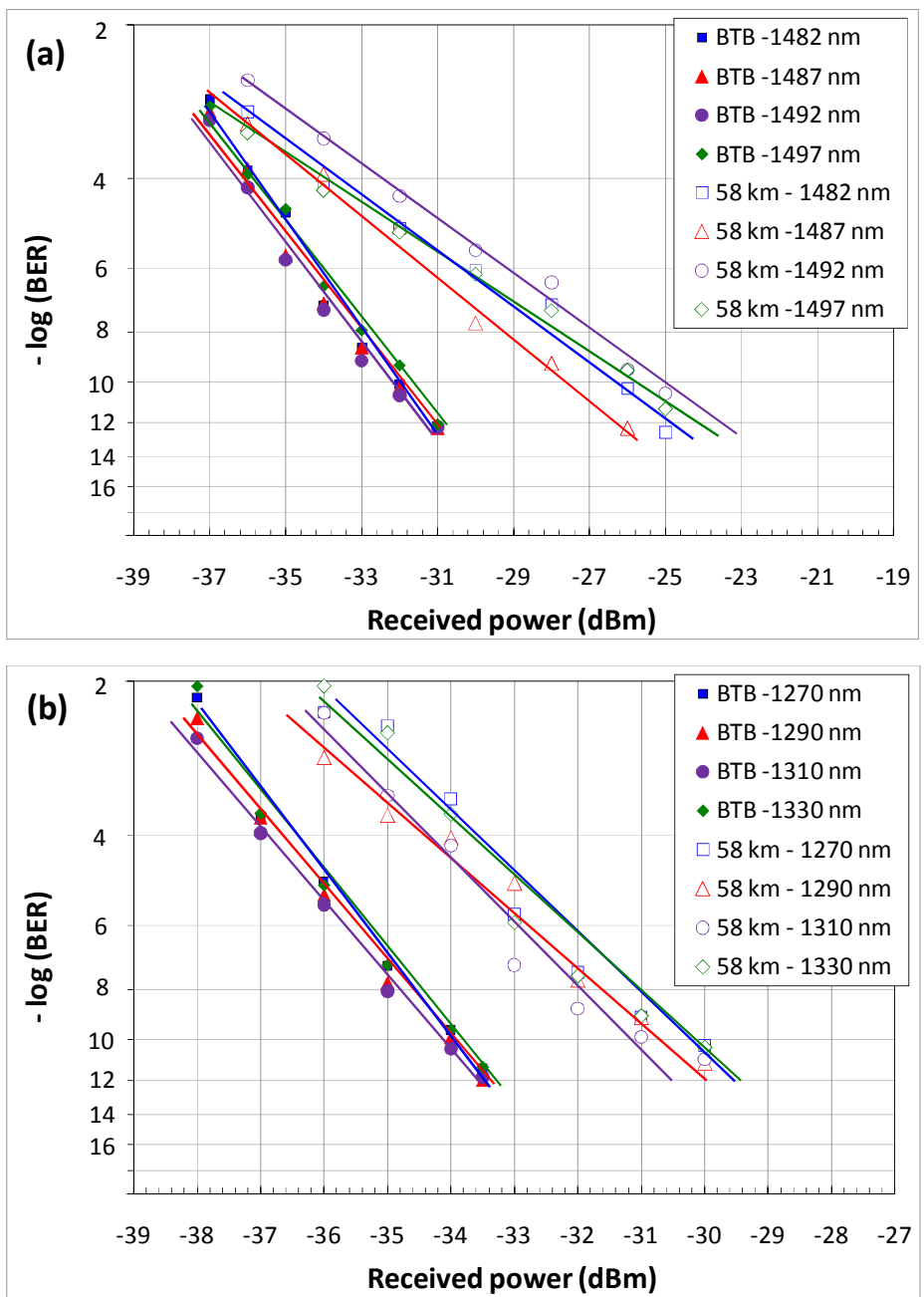

Fig. 10. The extended PON BER performance evaluation for (a) S band downstream channels measured in ONT and (b) O band upstream channels measured in OLT.

According this evaluation the maximum temperature operation for the $\mathrm{S}$ band lasers in this proposed system with no BER degradation is $35^{\circ} \mathrm{C}$, considering that a DFB lasers changes their 
wavelengths by $0.075 \mathrm{~nm} /{ }^{\circ} \mathrm{C}$. The $\mathrm{S}$ band mux and demux using dielectric filters technology could extend the operational temperature range since they have flat bandwidth, however they are not available in $\mathrm{S}$ band currently with $5 \mathrm{~nm}$ wavelength spacing.

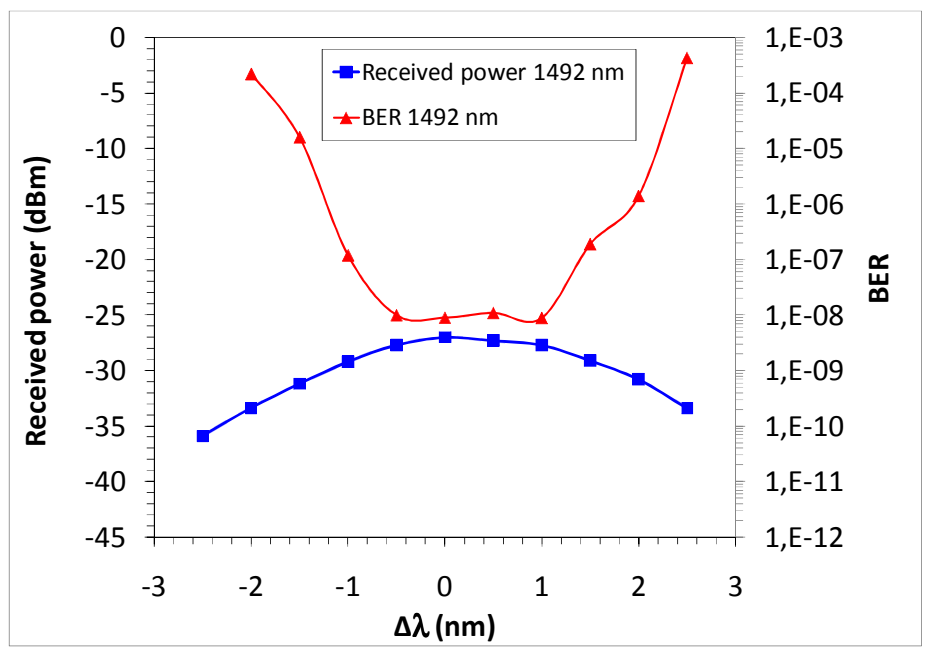

Fig.11. BER and received power performance of one $\mathrm{S}$ band channel (1492 nm) measured in ONT receiver when the laser wavelength is changed by $+/-2.5 \mathrm{~nm}$.

\section{CONCLUSION}

This paper has presented a new proposal to upgrade and to extend the currently PON by using WDM in the standard GPON or EPON optical grid. The aim is to increase the number of optical distribution networks powered by a single fiber while preserving the users' bandwidth. Four wavelengths channels are transmitted from the OLT to four different ODNs using the standardized ONT receiver ranging from 1480 to $1500 \mathrm{~nm}$. The upstream channels from the four different ODNs are also wavelength multiplexed using the standardized OLT receiver band spectrum ranging from 1270 to $1330 \mathrm{~nm}$. The network topology has been described and an experimental proof of concept has been presented. The good bit-error-rate performance presented by the proposal has shown its feasibility.

\section{REFERENCES}

[1] F. An, K. S. Kim, D. Gutierrez, S. Yam, E. Hu, K. Shrikhande, and L. G. Kazovski, "SUCCESS: a next-generation hybrid WDM/TDM optical access network architecture”, J. Lightwave Technology, Vol. 22, No 11, pp.2557-2569, November 2004.

[2] K. M. Choi, S. M. Lee, M. H. Kim, and C. H. Lee, "An Efficient Evolution Method from TDM-PON to NextGeneration PON”, IEEE Photonics Technology Letters, Vol. 19, No. 9, pp. 647-649, May 2007.

[3] S. Ahsan, M. S. Lee, S. H. S. Newaz, and S. Asif, "Migration to the Next Generation Optical Access Networks Using Hybrid WDM/TDM-PON", Journal of Networks, Vol. 6, No. 1, pp.18-25, January 2011.

[4] F. J. Effenberger, J. Kani, and Y. Maeda, "Standardization Trends and Prospective Views on the Next Generation of Broadband Optical Access Systems", IEEE Journal on Selected Areas In Communications, Vol. 28, No. 6, August 2010.

[5] T. Pfeiffer, "Enhancing PON capabilities using the wavelength domain", Join ITU-T/IEEE Workshop on Next Generation Optical Access Systems, Geneva, Switzerland, 2008.

[6] P. Solina, "European PON Deployments: A Carrier View of the Technical, Regulatory, and Economic Challenges", Proceedings of European Congress in Optical Communication ECOC 2010, paper We.8.B.1, Torino, Italy, 2010. 
[7] M. Bouda, P. Palacharla, Y. Akasaka, A.Umnov, C. Tian, and T. Naito, "Cost-Effective Optical Access Upgrades Using Wavelength Shared Hybrid Passive Optical Network Architecture", in National Fiber Optic Engineers Conference, OSA Technical Digest Series (CD) (Optical Society of America, 2007, paper NThD5.

[8] M. Bouda, P. Palacharla, Y. Akasaka, A.Umnov, and T. Naito, "Extended-Reach Wavelength-Shared Hybrid PON", in Optical Fiber Communication Conference and Exposition and The National Fiber Optic Engineers Conference, Technical Digest (CD) (Optical Society of America, 2008, paper NThD5.

[9] K. McCammon and S. Wong "Experimental Validation of an Access Evolution Strategy: Smooth FTTP Service Migration Path", in National Fiber Optic Engineers Conference, OSA Technical Digest Series (CD) (Optical Society of America, 2007, paper NThD5.

[10] G.984.2, "Gigabit-capable Passive Optical Networks (GPON): Physical Media Dependent (PMD) layer specification", ITU-T, 2003.

[11] J. Kani, "Enabling Technologies for Future Scalable and Flexible WDM-PON and WDM/TDM-PON Systems", IEEE Journal of Selected Topics in Quantum Electronics, Vol. 16, No. 5, pp.1290-1297, September/October 2010.

[12] G.694.2, "Spectral grids for WDM applications: CWDM frequency grid”, ITU-T, 2002.

[13] G.987.1, "10-Gigabit-capable passive optical networks (XG-PON): General requirements", 2010.

[14] G.983.3, "A broadband optical access system with increased service capability by wavelength allocation”, ITU-T, 2001.

[15] G.984.6, “Gigabit-capable passive optical networks (GPON): Reach extension”, ITU-T, 2008. 